\title{
TECHNOLOGICAL INNOVATION AND EMPLOYMENT: COMPLEMENTS OR SUBSTITUTES?
}

\author{
Autor: José Miguel \\ Benavente H. y Rodolfo \\ Lauterbach
}

Santiago, Oct. 2006

La serie de Documentos de Trabajo (SDT) del Departamento de Economía de la Universidad de Chile en versión PDF puede descargarse en la dirección electrónica www.econ.uchile.cl/SDT . Para contactar al editor ejecutivo de SDT remitirse a sdt@econ.uchile.cl 


\title{
Serie Documentos de Trabajo \\ N 221
}

\section{Technological Innovation and Employment: Complements or Substitutes?}

\author{
José Miguel Benavente $\mathrm{H}$. \\ Rodolfo Lauterbach \\ Departamento de Economía \\ Universidad de Chile
}

\begin{abstract}
In this paper we study the impact of innovation activities on employment. We develop an empirical strategy based on Jaumandreu (2003) whichaccounts for differences between product and process innovations. Using microdata at a firm level for the period 1998-2001, we found that product innovations affect positively and significantly employment levels in Chile. On the other hand there is no evidence to suggest that process innovations significantly affect employment after controlling for investment and sectorial patterns. These findings are of extremely interest in the current discussion about technological innovation policy in Chile.
\end{abstract}




\title{
Technological Innovation and Employment: Complements or Substitutes?
}

\author{
José Miguel Benavente \\ Rodolfo Lauterbach \\ First Draft (English not Revised) \\ 11 de agosto de 2006
}

\begin{abstract}
Resumen
In this paper we study the impact of innovation activities on employment. We develop an empirical strategy based on Jaumandreu (2003) which accounts for differences between product and process innovations. Using microdata at a firm level for the period 1998-2001, we found that product innovations affect positively and significantly employment levels in Chile. On the other hand there is no evidence to suggest that process innovations significantly affects employment after controlling for investment and sectorial patterns. These findings are of extremely interest in the current discussion about technological innovation policy in Chile.
\end{abstract}




\section{Introduction}

Innovation and employment are normally seen as substitutes. From an intuitive point of view improvements in productivity, obtained through an innovative process, will tend to diminish the demand of all productive factors for a given level of output which may affect employment negatively.

But this is only the first step. We also may think that increases on productivity could diminish production costs and under a competitive environment, these savings should be reflected on prices. Depending on the elasticity of the demand, total output may increase, affecting this time the employment in a positive way.

When doing a more exhaustive analysis of the relation between innovation and employment we should separate short term from long term effects, distinguishing between types of employment and types of innovation.

The impact of the innovative process in the long term is clearly non negative. During centuries, the industrial development has forced people to work for producing goods that in the past did not exist. Employment has not only grown but also it has diversified. At the same time the consumption of all economic sectors has increased as a compensation to the work effort. Nevertheless in the short term, when misalignments are taking place in the efficient allocation of factors and before the presence of information asymmetries, the effects of innovation on employment may go in both senses and differ between companies,industries, and even between countries.

The importance of this microeconomic analysis is that it allows us to obtain the percentage variations of the labor hiring in firms caused by the fact of having 
carried out some process or product innovations. This study tries to empirically evaluate the change on employment caused by innovations implemented in the manufacturing sector between 1998 to 2001.

The methodology used in this paper constitutes an ideal model to analyze the effects of innovation on employment at a firm level. An important characteristic of this approach is that it allows us to relate the change on employment in terms of the sales growth generated by new products and on the gains in productivity attributable to process innovations.

Results suggest that although improvements in productivity diminish employment, the increase in the total sales amount works like a compensation effect being the total effect positive. On the other hand product innovations only increase output and employment, if we asume that innovated goods are not merely substitutes of previous goods. We have not found evidence that allows us to affirm that process innovations affect significantly the firm's labour demand.

The rest of the document is structured as follows: Section 2 contains some conceptual considerations and previous empirical findings. Part 3 contains the specification of the model, in addition it exposes the use of instrumental variables. Part 4 includes the description of the data. In section 5 we present main results and section 6 concludes. 


\section{Innovation and Employment}

\subsection{Conceptual approach}

It has been, in a significant way, the invention of new products and processes what has taken the richest countries to its level of present consumption and well-being. And it is through the same way that developing countries like Chile must look for the sustaintability of their growth, at the moment dependant on the export of an exhaustible and probably replaceable natural resources.

Financial resources assigned by the companies to the development of innovation activities are frequently insufficient due to the existence of market failures. One of these has to do with the character of public good that may have the results of some specific investigations. Also information asymmetries in the technological markets exist. At the same time lack of experience and the high risk associated with $\mathrm{R} \& \mathrm{D}$ projects can take a company to optimally under invest in innovation activities.In addition, the credit market hardly finances an investigation project whose results are too uncertain to an attainable interest rate.

One of the most important aspects determining public and private effort in $R \& D$ is the impact of the innovative processes on the economic cycle and particularly on employment. Since finally all the economic agents involved and their incentives are those that take a company to decide its investment in $\mathrm{R} \& \mathrm{D}$, it is necessary to analyze the consequences that may have for these the products and process innovations.

Process innovations can reduce the amount of resources required for a given level of output, releasing resources to be used in other sectors. If the process in- 
novations allow to increase the productivity of a firm, it is expectable that this can maintain a same level of output using a smaller amount of factors and minor costs. The effect on the firm's labour demand depends on the current production technology and thus the substitutability between input factors, as well as on the direction of the technological change.

In this way, process innovations can destroy jobs diminishing the required amount of employment for a given output level. The magnitude of this effect will depend on if a particular process innovation is labour or capital augmenting.

On the other hand, compensation effects exist when the factors productivity increase is transferred to the final good prices, increasing the innovative firm's demand and output. This effect will depend on the magnitude of the diminution in the price, on the firm's demand price elasticity and on the competition of the market. While greater it is the competition, greater it will be the crossing of the diminution of costs to the prices. This mechanism can take to an increase on the firms'demand and thus process innovations can get to have a net effect on employment that is uncertain and must be studied.

At a macroeconomic level this effect can be reinforced by a greater activity in the inputs market that the innovating company uses for its production. When increasing the production of a firm that has made a certain process innovation, will positively increase the firm's input demand. This will stimulate the labour demand of the supplier companies. On the other hand, the competing companies that do not manage to reach the technological change required to reduce their costs will tend to disappear of the market, being generated an employment diminution. 
In the model used i this study we observe the companies that remain in the market. We do not observe the companies that enter or exit the market causing important changes on employment and whose entrance or exit can be the result of innovation processes.

This study aims to find the existing relation at level of firms between innovation and employment. It is important to emphasize that this microeconomic analysis cannot be used to obtain the added impact of innovation on employment by means of multiplying the effect by the number of firms in the market.

Since this analysis is at a firm level, the sales growth due to innovation processes cannot be separated between market expansion and changes on its composition. If the sales growth generated by innovation processes had to do with changes in the market composition and not with a net expansion of the market, the added impact of innovation on employment would be minor than the effect at the firm level.

When a firm introduces a new product to the market, it will generate an increase on the firms'demand. This effect on the demand of the firm must be separated in two parts. On the one hand there is the expansion of the market generated by the new product. On the other hand, a change in the composition of the market in favor of the innovating company can exist. The magnitude of the expansion of the sales and its permanence in the time will also depend on the delay of the competitors'reaction and on the competition level of the market. ${ }^{1}$

\footnotetext{
${ }^{1}$ For a detailed explanation on this point see Garcia et al (2002)
} 
Additional effects exist on employment when introducing a new product if there is a substitutability degree between the new product and the old products. In this case labour demand for the production of the old good will diminish and the total effect on employment is again uncertain.

Product innovations also can have an effect on productivity, the impact of these effects on employment will depend on the proportions of capital and work used in the production of new products.

\subsection{Previous empirical findings}

From the empirical works that discuss the existing firm-level relation between innovation and employment it is possible to distinguish between two main subjects. The first is the impact of technological change in the total amount of employment at the firm level, and the second is the impact of the technological change on the structure of the employment, distinguishing between jobs with different levels of specialization.

\subsubsection{The impact of the technological change in the total amount of employment}

Alonso-Borrego and Collado (2001) consider the effects of innovation on employment in Spain. The model consists of a two steps procedure that considers the fact that companies endogenously choose a change in employment that can be positive, negative or equal to zero, in which the selection mechanism is an ordered probit. Their results show that companies that innovate create more jobs and destroy less than those which do not innovate and the degree of innovative effort generates a positive impact on employment generation. 
García, Jaumandreu and Rodriguez (2002) develop and consider a model with the effects of innovative activities on the labor hiring of the companies in Spain using the survey ESEE, a firm level panel survey of Spanish manufacturing starting in 1990. They find that the potential compensation effect is greater than the displacement effect of employment generated by product innovation not only in the short term but also in a long term horizon when competitors react. Their results find that product innovation duplicates the effects of employment expansion by cost unit but that the behavior of the agents can reduce this impact severely.

Piva and Vivarelli (2003) study the impact of innovation on employment in Italian companies in situations where intermediate technologies have been implemented, mainly through the gross investment on innovation in the Italian manufacturing industry. Between its results a positive, significant but small effect of innovation on employment is found.

Jaumandreu (2003) develops and considers a model that relates employment growth to process innovations and to the sales growth due to old and innovated products using Spanish data of survey CIS3. He finds that process innovation does not displace employment and that product innovation expands employment with a gross unit elasticity with respect to innovative sales.

Peters (2004) made a study using the data of survey CIS3 for Germany. Her results show that product innovations have a positive impact on employment. The effect found is independent if innovated products correspond to new features for the single market or only new to the firm. With respect to the effect of process innovation in the manufacturing sector, the displacement effects surpass to the compensation effects causing a negative impact on employment. Nevertheless in 
the services companies the process innovation does not have a significant impact.

Harrison, Jaumandreu, Mairesse and Peters (2005) study the impact of process and product innovations on employment using the data of survey CIS3 for France, Germany, Spain and the United Kingdom. Their results for the manufacturing industry conclude that although process innovation tends to move employment, compensation effects are more important. With respect to product innovation it is associated with growth on employment.

\subsubsection{The impact of the technological change on the on employment structure}

With respect to the impact of the innovation on the composition of employment Chennells and Van Reenen (1999) obtain a robust positive effect of technology on the abilities of the contracted employees, suggesting that technology has, on average, a slant towards the hiring of more skilled employees. On the other hand their results show evidence of a positive correlation between wages and innovation. Also they find that product innovations seem to elevate employment growth, but do not obtain evidence of a robust effect of the process innovations or $\mathrm{R} \& \mathrm{D}$ expenditure on employment.

Zwick (1999) concludes that innovation induces to the obsolescence of the abilities and the investment in human capital becomes more necessary to greater obsolescence of the old abilities.

According to the results found by Falk (1999) innovation of products that are new for the market is on average most important to determine the growth of its expected labor hiring. The effect of the incorporation of new product for 
the market on the expected growth of employment is greater for greater levels of education of the workers.

Janz and Peters (2002) have concluded that the probability of making product innovation increases with the size of the firm and with the human capital of its workers. They also find that the success of innovation, measured by the innovated product sales, increases with the effort of innovation and the proportion of workers highly skilled.

\section{The Model}

The following model is widely based on the study of Harrison, Jaumandreu, Mairesse and Peters (2005) developed and applied to a comparable sample of four European countries, using the data of survey CIS3 of Innovation, in the European Community. The model, that was firstly developed by Jaumandreu (2003) and it was also used with some extensions by Peters (2004), allows us to separate some of the effects of product and process innovation on employment at level of firms.

\subsection{Basic concepts}

This model is based on the idea of a firm with a production function according to which it can produce two different products. The firm decides if it produces new products or not during the reference period. In the beginning of the period the firm produces products grouped in an added production called .ld products"that corresponds to the value of $Y_{11}$. During the period of reference the firm can decide to add new or significantly modified products to its production to commercialize them in the market. These products, in ahead called "new products", are grouped under the value of $Y_{22}$. 
We suppose that the decision to innovate is previously determined with respect to the decision of hiring for a period. If the decisions to innovate and to contract were determined jointly we would may have an endogeneity situation. The new products can replace the old ones if these are substitutes or can increase their demand if they are complements. The change in the production of the old products is denoted by $\Delta Y_{11}$. In addition, it is understood that the new product output in the beginning of the period is equal to zero $Y_{21}=0$ and the production of the ${ }^{\circ}$ ld products. ${ }^{a}$ the end of the reference period is denoted by $Y_{12}$.

In order to produce different amounts of goods, it is assumed that firms must weigh the conventional factors - work, capital and materials, in equal proportions since the production function is linear-homogenous for these factors. By simplicity we assume that work is an homogenous factor. Nevertheless a knowledge capital exists that is a non rival factor for the productive processes and that leads to specific efficiencies for each process.

Equations (1) and (2), for the production of the old product in the beginning and at the end of the period, can be deduced after the three following statements. (i) The knowledge proportionally increases the marginal productivity of all conventional factors by means of an efficiency parameter $\Theta_{\jmath}$, for $\jmath=1,2$ (ii) the efficiency in the productive process of old products can increase by $\Delta \Theta_{1}$, is to say due to process innovations, learning effects or exogenous technological progress, and (iii) there are no economies of scale.

$$
\begin{gathered}
Y_{11}=\Theta_{1} \cdot F\left(L_{11}, K_{11}, M_{11}\right) \\
Y_{11}+\Delta Y_{11}=\left(\Theta_{1}+\Delta \Theta_{1}\right) \cdot F\left(L_{11}, \Delta L_{11}, K_{11}, \Delta K_{11}, M_{11}, \Delta M_{11}\right)
\end{gathered}
$$


Now the production of the new product at the end of the period is given by (3):

$$
Y_{22}=\Theta_{2} \cdot F\left(L_{22}, K_{22}, M_{22}\right)
$$

where $\Theta$ represents efficiency, $L, K$ and $M$ represent work, capital and materials respectively. The cost function of the firm can be described on equation (4).

$$
C\left(\omega_{1 t}, \omega_{2 t}, Y_{1 t}, Y_{2 t}, \Theta_{1 t}, \Theta_{2 t}\right)=c\left(\omega_{1 t}\right) \frac{Y_{1 t}}{\Theta_{1 t}}+\left(\omega_{2 t}\right) \frac{Y_{2 t}}{\Theta_{2 t}}+F
$$

where $c(\omega)$ is the marginal cost (a function of prices of factors $\omega$ ) and $F$ is an arbitrary and exogenous fixed cost. According to the Shephard's Lemma, we have:

$$
L_{\imath t}=c_{L}\left(\omega_{\imath t}\right) \frac{Y_{\imath t}}{\Theta_{\imath t}}
$$

where $c_{L}\left(\omega_{\imath t}\right)$ represents the derivative of the marginal cost with respect to the wage.

\subsection{The employment equation}

Employment growth during the period can be separated into employment growth due to the production of the old product, and employment growth due to the production of the new product in the following way (notice that $L_{21}=0$ ).

$$
\frac{\Delta L}{L}=\frac{L_{12}-L_{11}}{L_{11}}+\frac{L_{22}}{L_{11}}
$$

We assume that the derivative of marginal cost with respect to the wage does not change over the period, thus $c_{L}\left(\omega_{11}\right)=c_{L}\left(\omega_{12}\right)=c_{L}\left(\omega_{1}\right)$. This will be the case, for example, if the relative prices are constant during the period. ${ }^{2}$

\footnotetext{
${ }^{2}$ Notice that $c($.$) is homogenous of degree one and therefore c_{L}($.$) is homogenous of degree$
} zero. 
Using the results of the previous section we can write an approximated decomposition of the employment growth in the following way

$$
\frac{\Delta L}{L} \cong-\left(\frac{\Theta_{12}-\Theta_{11}}{\Theta_{11}}+\frac{Y_{12}-Y_{11}}{Y_{11}}+\frac{c_{L}\left(\omega_{2}\right) \Theta_{11} Y_{22}}{c_{L}\left(\omega_{1}\right) \Theta_{22} Y_{11}}\right)
$$

where we have used a linear approach to obtain the two first terms.

This expression says that employment growth is the result of (i) the change in the efficiency of the production process of the old products (that affects negatively the labour demand), (ii) the rate of change of the production for these products (caused in certain degree by the new product, this effect would have to be negative if both products are substitutes and positive if they are complements), and (iii) the output expansion attributable to new products (positive sign).

The increase on the efficiency of the old processes of production $\left(\frac{\Theta_{12}-\Theta_{11}}{\Theta_{11}}\right)$ is expectable to be greater for the companies that introduce process innovations that are related to the old product, although the efficiency of all the companies can grow with time. If we assume that the derivative often marginal cost with respect to the wage is equal for old and new products, that is to say, $c_{L}\left(\omega_{1}\right)=c_{L}\left(\omega_{2}\right)^{3}$, then the effect of product innovation on employment growth depends on the difference on efficiency between the production processes of old and new products (the ratio $\frac{\Theta_{11}}{\Theta_{22}}$.

If the new products are produced in a more efficient way than old products then this ratio will be less than unity and employment does not grow one by one with the growth of the production due to new products. If the derivative of the marginal cost with respect to the wage is greater for new products (if

\footnotetext{
${ }^{3}$ This will be the case if, for example, the relative prices of factors are equal for both products. In fact it is quite probable that the relative prices of factors are equal for both products.
} 
$\left.c_{L}\left(\omega_{1}\right)<c_{L}\left(\omega_{2}\right)\right)$, then the considered ratio is slanted upwards, in other words the increase of the associated efficiency in new products is underestimated.

Transforming our economic model into an econometric model we can see that equation (8) suggests the following population relationship

$$
\ell=\alpha+y_{1}+\beta y_{2}+\mu
$$

with

$\ell$ : employment growth in the period

$y_{1}$ : real output growth due to old products

$y_{2}$ : real output growth due to new products

$\mu$ : random error with zero mean

$\alpha$ : (less) average efficiency growth in the production of the old product

$\beta$ : new and old product relative efficiency

It is possible to extend the equation (8) and to arrive at expression (9) assuming two things. In the first place that gains in efficiency are probably different between process innovators and non process innovators. Secondly, assuming that the process innovations only affect the production technology of old products. ${ }^{4}$

$$
\ell=\alpha_{0}+\alpha_{1} d+y_{1}+\beta y_{2}+\mu
$$

with

$\ell$ : employment growth rate

$\alpha_{0}$ : (negative) average efficiency growth for non-process innovators

$\alpha_{1}$ : average efficiency growth for process innovators

d: dummy variable indicating process innovations

\footnotetext{
${ }^{4}$ See Harrison et al (2005: 10) for a more exhaustive analysis of this point.
} 
$y_{1}$ : real output growth due to old products

$y_{2}$ : real output growth due to new products

$\mu$ : error term with $E(\mathrm{u} \mathrm{j} \mathrm{d} ; \mathrm{y} 1 ; \mathrm{y} 2)=0$

In order to compare (8) or (9) with other specifications, it is necessary to notice that (9) can simply be transformed into a productivity growth equation by rearranging the terms of the equation as follows.

$$
y_{1}+y_{2}-\ell=-\alpha_{0}-\alpha_{1} d+(1-\beta) y_{2}-\mu
$$

This way, the output growth per worker positively depends on process innovations and the expected sign for product innovation depends on the relative efficiency of the new and old processes. If $\beta$ is equal to one, the efficiency is the same one for both processes and the new products do not affect the productivity per worker. If $\beta$ is minor to one, the new products are produced in a more efficient way, and thus the output growth due to new products increases the productivity per worker.

The equations (8) and (9) contain rates of growth of the variables. A clear possibility that exists is that the error term contains shocks of productivity correlated with the introduction of process or product innovations (for example investments, reusability of idle capacity, organizational problems). Nevertheless, we will suppose that in the long term there are no productivity growth determinants in the error term that are correlated with process or products innovations. In any case, we must consider that, if this last assumption is not truth, a positive correlation between the introduction of innovations and not observed favorable shocks of productivity would induce a negative slant in our estimations $\alpha_{1}$ and $\beta$. That is to say, we would consider displacement effects of employment caused by process and products innovations that would be too large. 
Equation (9) implies that even non process innovating companies can reach gains in efficiency during the period, possibly due to exogenous technological changes.

\subsection{Adjustments to the model}

If we assumed that all the variables of the right side of equation (9) are independent of each other and with an error term which is distributed normal with average 0 , constant variance and not auto correlated, this equation could give us unbiased and consistent estimators for the parameters of the model. Next we will comment the necessary conditions for the fulfillment of these assumptions and we will specify some corrections to the model exposed until this point.

In the first place, the variable $y_{1}$ contains three different effects that cannot be separated in absence of additional data: (i) the independent increase of demand by old products of the firm, (ii) the compensation effects induced by possible prices variations resulting from a process innovation, and (iii) the demand's substitution effect resulting from the introduction of new products to the market. Since we cannot separate these three effects, actually $y_{1}$ simply will be reduced to both sides of the equation, with which it will appear reduced from $\ell$.

In second term, under the assumption that the output growth due to the introduction of new products $\left(y_{2}\right)$ is an observed variable, equation (9) shows clearly the effect of the production of new goods on employment. A first problem is that the real rate of growth of the sales of new products $\left(y_{2}\right)$ is a non observed variable. In order to estimate equation (9) we must divide the observed nominal growth of the firms sales into the growth of sales due to old products $\left(g_{1}\right)$ and due to new products $\left(g_{2}\right)$. The non observability of the prices is common on pro- 
ductivity analysis, but it acquires special relevance in this case since we want to separate the effects of productivity generated by old and new products, which can be sold to different prices. If $\left(g_{1}\right)$ is the nominal sales growth and $\pi_{1}$ is the rate of increase of the prices of these products during the period, we can describe the approach $g_{1}=y_{1}+\pi_{1}$ where $y_{1}$ is the not observed real sales growth of old products.

Now, if $g_{2}$ is the nominal sales growth due to new products and $\pi_{2}$ is the change in the prices of new products with respect to the prices of old products, then we can say that $g_{2}=y_{2}\left(1+\pi_{2}\right)=y_{2}+\pi_{2} y_{2}$ where $y_{2}$ is the unobserved real sales growth due to new products.

Replacing $g_{1}$ and $g_{2}$ in equation (9) and rearranging the equation we have:

$$
\ell-g_{1}=\alpha_{0}+\alpha_{1} d+\beta g_{2}+\nu
$$

where the new unobserved error term is $\nu=-\pi_{1}-\beta \pi_{2} y_{2}+\mu$. In case that $\pi_{1}$ has an average different from zero the model will include $-E\left(\pi_{1}\right.$ in the intercept and $\mathrm{y}-\left(\pi_{1}-E\left(\pi_{1}\right)\right.$ in the error term. We assumed that $\pi_{2}$ has a zero mean independent of $y_{2}$, is to say ${ }^{5} E\left(\frac{\pi_{2}}{y_{2}}\right)=0$. Then $E\left(\pi_{2} y_{2}\right)=0$ and $\pi_{2} y_{2}$ are not correlated with $y_{2}$ (although more likely they are correlated).

In order to consider the parameters of the equation (11) we will have to face three important problems. First, $g_{2}$ is an endogenous variable, in the sense that it is correlated with $\pi_{2}$ which is part of the error term. We can try to solve this problem using instrumental variables for $g_{2}$ that are correlated with $y_{2}$ but that are not correlated with the change in the prices.

\footnotetext{
${ }^{5}$ The sales of new products will depend, among other things, negatively of the price of new products, this is due to demands'price elasticity. In addition they will depend on the price of old products due to the demands'crossed elasticities.
} 
The instrument that will be used is the degree of the firmsútilization of novel inputs, as an origin of the innovation ideas. ${ }^{6}$ The variable taking the value zero if the innovation idea does not have any relation with the use of novel inputs, and takes values between 1 and 4 according to the level in which the firm declares to have used novel inputs. Whereas the innovation activities could not be exogenous with respect to employment growth, it is possible that the use of novel inputs as an origin of innovation ideas is.

Secondly, the error term is including the variable $\pi_{1}$ that represents the change in the prices of old products, this way we cannot control by $\pi_{1}$. This generates a specification problem in the model. In this model we will use a price index system $\pi_{1} *^{7}$, calculated with a disaggregation of the industry, like a proxy for $\pi_{1}$. Thus we will use $\ell-\left(g_{1}-\pi_{1} *\right)$ as a dependent variable what will leave $-\left(\pi_{1}-\pi_{1} *\right)$ in the error term. With this adjustment we will be able to identify the real average productivity effect, but we will continue having an identification problem for the companies that turn aside of the awaited behavior of fixation of prices. This is, if the individual differences in the behavior of fixation of prices $-\left(\pi_{1}-\pi_{1} *\right)$ are, as it is probable, related to the individual differences of growth of efficiencies, then the problem of identification is only partially corrected.

It is important to emphasize that the growth rates $g_{1}$ and $g_{2}$ are not observed directly but they are constructed from observations of the rate between new and old products in the total sales at the end of the analyzed period, s, and from the rate of growth of the total sales, $g$. Then $g_{2}=s(1+g)$ and $g_{1}=g-s(1+g)$.

\footnotetext{
${ }^{6}$ The correlation between this instrument and the instrumentalized variable is 0.24 .

${ }^{7}$ This index has been obtained from the work by Benavente et al (2005)[5].
} 
Finally if we assume (i) that the exogenous technological changes are not related to the participation of the firm in some process innovation ${ }^{8}$ and (ii) that they are not related either to the error term, the parameter $\alpha_{1}$ would show us the average efficiency growth for all the innovating and non innovating companies, and the parameter $\alpha_{1}$ would give us the average growth of additional efficiency for the companies that make process innovation.

\footnotetext{
${ }^{8}$ This is possible, for example, under the assumption that exogenous technological change comes from outside of the companies as a set of shocks and that this is, on average, identical for all the companies of an economy.
} 


\section{Description of the Data}

This study has been made with the data of the " ${ }^{r d}$ Survey of Technological Innovation and Productivity in the Manufacturing, Mining and Power Industry"made by the Chilean National Institute of Statistics. The survey collected data on 560 firms in all the regions of Chile in 2001. Also the "National Survey of the Manufacturing Industry. ${ }^{\circ}$ years 1998 to 2001 has been used to obtain the change in employment and productivity in the reference period.

In this section we summarize the most important characteristics of the data. Table 1 shows the sales, employment and prices growth, for period 1998-2001 in Chile. A distinction between product innovating companies, process innovating companies and non innovating companies is made. It is distinguished between companies that have introduced only process innovations and companies which have introduced product innovations having or not also introduced process innovations. For simplicity, it has been preferred not to distinguish between those companies that have introduced product and process innovations of which that have introduced product innovations only. This is due to the characteristics of the data which do not allow to observe if both types of innovation are determined jointly.

Making the sum between process innovators only and product innovators, the total percentage of companies that makes some type of innovation is obtained, this cipher is equivalent to $82 \%$ of the 558 companies included in the sample.

In table 1 we can see that those companies that do not make innovation register an average diminution on their hiring of personnel. The companies that make only process innovation register an increase of $25 \%$ on their employment, whereas 
product innovators or product and process innovators register an average increase on employment superior to $6 \%$.

The total sales register an important average increase of $30 \%$ during the period for the total of the sample. This increase is reduced to only a $9 \%$ for the case of the non innovating companies, whereas for process innovators it is a $29 \%$ and for product innovators a $34 \%$.

The new and old product sales are considerably greater for the case of the companies that make some type of innovation compared to which that have not declared to innovate in their processes nor in their products.

In the case of the only process innovating companies, the sales of old products increases in average during period 1998-2001 in more than a $16 \%$. On the other hand, the new products sales growth for the product innovating companies reaches a $29 \%$ average during the same period.

Finally table 1 shows us that the average prices change during the studied period is near $17 \%$. On the other hand we see that productivity increases much more on innovating companies than on the non innovating companies. Whereas in the companies that do not innovate the productivity increases on 2,6\% average, on only process innovators this number rises to $13,2 \%$ and on product innovators to $7.7 \%$. 


\section{Results}

In the first place, we have briefly reviewed the conditional relations that we suppose exist between the variables from our theoretical model. Table 2 presents an OLS estimation, where the dependent variable is the change in the total employment during the period. The independent variables are the total sales growth fit by the prices increase, a dummy variable for . ${ }^{\circ}$ nly process innovation", another dummy for "product innovation", and the control variables.

The coefficient on real sales growth turns out to be very significant and in addition its value is far below unity, reason why we can conclude that although the increase on sales is positively correlated with employment, this increase is associated to a growth of smaller magnitude on employment.

The coefficients of the variables . ${ }^{\circ}$ nly process innovation. ${ }^{a}$ nd "product innovation. ${ }^{a}$ re nonsignificant, not being able to give empirical evidence with respect to their impact on employment.

These results are little useful to define the displacement and compensation effects of the development of innovation tasks with respect to employment growth at level of the companies. For this reason, next we will use the structure of our theoretical model and also information on the participation of new and old products in the total sales.

\subsection{Employment effects of product innovations}

Table 3 displays the results of considering (8) after replacing $y_{1}$ by $g_{1}$ and rearranging the equation. The dependent variable is the employment growth mi- 
nus the growth of the sales due to old products fit by a prices index of each economic sector. Now, according to the model that we have specified, the value of the constant is an estimation (with negative sign) of the average growth in real productivity (in a 3 year period) on the production of the old goods, after any compensation effect of the prices. The regressions have been controlled by economic sector and the investment during the period like proportion of the total income.

Panel A presents the results of the OLS regression. The coefficient that accompanies the variable "new product sales growthrepresents an estimation of the relative efficiency between production of the new and old product. Since this value is far below unity and it turns out to be significant, we can conclude that the new products are produced with smaller amount of work than old products, is to say with a greater level of efficiency.

In panel B a 2 stages square minimums approach has been made. The variable "new product sales growth"has been considered as an endogenous variable and a single instrument has been used (the equation this exactly identified). The appropriate instrument for this case is which that is related to the new products sales but not to the prices changes of new products compared with old products. The instrument used is the degree of usage on the part of the company of novel inputs, as an origin of the innovation ideas ${ }^{9}$.

The variable takes value zero if the innovation idea does not have any relation with the use of novel inputs, and takes values between 1 and 4 according to the level in which the company declares to have used novel inputs as an origin to

\footnotetext{
${ }^{9}$ The correlation between this instrument and the instrumentalized variable is 0.24
} 
the innovation ideas. Whereas the innovation activities could not be exogenous with respect to employment growth, it is possible that the usage of novel inputs as an origin of innovation ideas is. We have tried to prove the true exogeneity of the instrument by means of over identifying the restrictions on an over identified specification in panel C.

The estimation of the coefficient "sales growth due to new products"is considerably greater than the OLS estimation. This is consistent with a negative slant due to not observed price changes on the OLS estimation. The considered coefficient is even far below to one what allows us to think that the new goods are produced with a greater level of efficiency than the old goods. From the constant we can obtain an estimation of the average growth of the productivity (in a 3 year period) on the production of old goods and that is near to $0.8 \%$.

We have proven the validity of the instrument by means of the usage of an over identified model specification. The additional instruments that we have used are the degree of impact of the innovation in the increase of the range of goods produced by the company, the utilization of clients as source of information for the innovation process, and permanent $R \& D$ engagement. This instruments have a smaller correlation with the instrumentalized variable that the instrument used in the previous regression. Nevertheless we have no reason to think that this variables could be related to the change in the prices of new products compared with old products. When doing the comparison between panels B and C we can conclude that the estimation is robust to the inclusion of the new instrument, throwing equally significant parameters. 


\subsection{The effects of process innovation on employment}

In table 4 the obtained results are transformed using the specification of the model expressed in the equation (11). That is to say, also allowing that the process innovation affects the growth of productivity and, therefore, it influences the change of the employment. The dependant variable is employment growth minus the growth of the sales due to old products fit by an index of prices of products. Now, according to the model that we have specified, the value of the constant is an estimation (with negative sign) of the average growth of the real productivity (in a period of 3 years) on the production of the old goods, after any compensation effect of the prices. The regressions have been controlled by economic sector and investment during the period as a proportion of the total income.

Panel A presents the OLS results. The value of the coefficient "new product sales growthrepresents an estimation of the relative efficiency between the new and old product output. Since this value is significant and smaller than one, we can conclude that the new products are produced with smaller amount of work than old products, is to say with a greater level of efficiency. On the other hand, as the sign of this coefficient is positive we suppose that product innovation positively affects the total amount of employees that a company hires. The coefficient that accompanies the variable . ${ }^{\circ}$ nly process innovation"is very small and nonsignificant reason why it does not offer us any evidence about the impact of process innovations on the level of hiring of the companies.

In panel $\mathrm{B}$ an estimation by instrumental variables has been made. The instrument used is the degree of use on the part of the company of novel inputs, as an origin of the innovation ideas. The estimation of the coefficient "sales of new products" is considerably greater than the estimation by OLS. This is consistent 
with a negative slant due to non observed prices changes in the estimation by OLS. The considered coefficient is even far below to one, what allows us to think that the new goods are produced with a greater level of efficiency than the old goods. The coefficient that accompanies the variable . ${ }^{\text {only }}$ process innovation"is very small and nonsignificant reason why it does not offer us any evidence about the impact of the process innovations on the level of hiring of the companies.

In panel $\mathrm{C}$ we have added an instrument to evaluate the validity of the specification of panel B. The additional instrument that we have used is the degree of impact of the innovation in the increase of the range of goods produced by the company. If well this instrument has a smaller correlation with the instrumentalized variable than the instrument used in the previous regression, it does not seem to be any reason to think that this variable could be related to the change in the prices of new products compared with old products. When doing the comparison between panels $\mathrm{B}$ and $\mathrm{C}$ we can conclude that the estimation is robust to the inclusion of the new instrument, throwing equally significant parameters. 


\section{Concluding Remarks}

This study has consisted in the accomplishment of a valuation of the impact of the process and products innovations on the change of the total employment at level of companies of Chile for period 1998-2001. For this effect the data of " $3^{r d}$ Survey of Technological Innovation and Productivity in the Manufacturing, Mining and Power Industry. ${ }^{a}$ nd of the "National Survey of the Manufacturing Industry. ${ }^{\circ}$ years 1998 to 2001, made by the National Institute of Statistics, have been used.

Within the main results of this study there is evidence to affirm that product innovations positively and significantly affect the total amount of employees demanded by the Chilean companies. The existing problems of endogeneity because of the non observability of the difference between the prices of old and new products, have been corrected by means of the intrumentalization of the variable "new products sales growth", obtaining significant and agreed parameters with our theoretical model.

The value of the parameter calculated for this last variable, by means of the use of instrumental variables, fluctuated between 0,52 and 0.54. This means that although the sales increase of new products is positively correlated with employment growth, it is associated to a growth of smaller magnitude on employment. We can conclude that new products are produced with smaller amount of work than old products, it is to say, with a greater level of efficiency.

Secondly we have found evidence to maintain that productivity growth of the companies including in the sample in a 3 year period is approximately a $0.8 \%$. This productivity increase negatively influences the existing ratio between em- 
ployment and output. Nevertheless the increase maintained in the sales of old products of the companies has allowed the employment to grow, in spite of existing productivity growth in the companies.

When including process innovation in the model, we have not found evidence that this affects somehow significantly the change on employment of the companies including in the sample.

The model developed by Jaumandreu (2003)[21] has constituted an important contribution to the literature that studies innovation and the relation between this and the evolution of employment of the innovating companies. Future investigations that are made could extend this model towards the analysis of different types of employment (described and not described). 


\section{Variable Definitions}

- Clients as source of information: Variable that takes value 0 if the company informs that it has not used clients as a source of information for the innovation process, and values from 1 to 4 according to the intensity of use of clients as a source of information.

- Permanent R\&D engagement: Variable dummy that takes value 0 if the company reports not to have $R \& D$ department and 1 in the opposite case.

- Employment growth: $\frac{\text { empl2001-empl1998 }}{\text { empl1998 }}$ rate of change of total employment of the company throughout the period.

- Increase in the product range: Variable that takes value 0 if the company reports that the effect of the innovation has been irrelevant for the range of goods produced by the company; and values between 1 and 8 according to the intensity in which the innovation has increased the range of products.

- Novelty degree: variable that takes value zero if the innovation idea does not have any relation with the use of novel inputs, and takes values between 1 and 4 according to the level in which the company declares to have used novel inputs as an origin to the innovation ideas

- Effort in R\&D: rate between total cost in R\&D and income.

- Investment/Sales: proportion of the income inverted during the period.

- Processes and products innovation: Dummy variable that takes value 1 if the company reports to have introduced new or significantly improved products and also to have introduced new or significantly improved processes during the period; and it takes value 0 in another case. The innovation of design and packing has been considered product innovation. 
- Process innovation: Dummy variable that takes value 1 if the company reports to have introduced new or significantly improved processes during the period; and takes value 0 in another case. The innovation of the administrative management has been considered process innovation.

- Only process innovation: Dummy variable that takes value 1 if the company reports to have introduced new or significantly improved processes during the period but no new or significantly improved products.

- Growth of the sales: $g=\frac{P_{22} Y_{22}+P_{12} Y_{12}-P_{11} Y_{11}}{P_{11} Y 11}$ Rate of growth of the total sales during the period

- Proportion of innovated products $S=\frac{\text { newproductsales }}{\text { totalsales }}$

- Sales growth due to new products: $g_{2}=s(1+g)$

- Sales growth due to old products: $g_{1}=g-s(1+g)$ 


\section{Referencias}

[1] Ahn, Sanghoon, (2002) Çompetition, Innovation and Productivity Growth, a review of theory and evidence". Organisation for Economic Co-operation and Development.

[2] Alonso-Borrego, C., Collado, M., (2001), "Innovation and Job creation and Destuction, evidence from Spain", Departamento de Estadística y Econometría Universidad Carlos III de Madrid.

[3] Bassanini, Andrea and Ernst, Ekkehard (2002) "Labour Market Institutions, Product Market Regulation,and Innovation Cross-Country Evidence", Organisation for Economic Co-operation and Development

[4] Benavente, Jose Miguel (2005), . ${ }^{A}$ ntecedentes para el diseño de una política tecnológica nacional", Informe Técnico para la comisión de Hacienda del Senado de la Republica de Chile.

[5] Benavente, J., De Gregorio, J., Nuñez, M., Rates of Return for Industrial R\&D in Chile", Department of Economics, University of Chile and Central Bank of Chile.

[6] Características de la Innovación Tecnológica en las Empresas Españolas, Banco de España, Boletín Económico, Junio 2005.

[7] Chennels, L., Van Reenen, J., (1999), "Has Technology Hurt Less Skilled Workers", Institute for Fiscal Studies.

[8] Crepon, B., Duguet, E., Mairesse, J., (1998), Research, Innovation, and Productivity An Econometric Analysis at the Firm Level", NBER working paper series. 
[9] Falk, M., (1999), "Tecnological Innovations and The Expected Demand for Skilled Labour at the Firm Level". Centre for European Economic Research (ZEW)

[10] García, A., Jaumandreu, J., and Rodríguez, C., (2002), "Innovation and Jobs Evidence From Manufacturing Firms", "Innovation and employment in European Firms, "supported by the European Commission.

[11] Garcia, A., Rodríguez, C., Jaumandreu, J., (2002), "Innovación y empleo evidencia a escala de empresa", Economia Industrial Nž 348.

[12] Geroski, PA., (1995), "Innovation and Competitive Advantage", Economics Department Working Paper, OECD.

[13] Grifith, R., Huergo, E., Mairesse, J., Peters, B., (2005) "Innovation and Productivity across Four European Countries", "Innovation and Employment in European Firms: Microeconometric Evidence (IEEF)", funded by the European Commission.

[14] Griffith, R., Redding, S., Simpson, H., (2002), "Foreign Ownership and Technological Convergence at the Micro Level", Institute for Fiscal Studies.

[15] González, X., Jaumandreu, J., and Pazó., (2004), "Barriers to innovation and subsidy effectiveness", The Rand Journal of Economics.

[16] Harrison, R., Jaumandreu, J., Mairesse, J., Peters, B., (2005), "Does innovation stimulate employment A firm-level analysis using comparable micro data from four European Countries". European research project Innovation and Employment in European Firms: Microeconometric Evidence (IEEF). 
[17] Huergo, E., Jaumandreu, J., (2002), "How Does Probability of Innovation Change with Firm Age", Universidad Complutense y Universidad Carlos III, Madrid.

[18] Huergo, E., Jaumandreu, J., (2003), "FirmsÁge, Process Innovation and Productivity Growth", Universidad Complutense y Universidad Carlos III, Madrid.

[19] Janz, N., Lööf, H., and Peters, B., (2003), "Firm Level Innovation and Productivity Is there a Common Story Across Countries", Centre for European Economic Research. Janz, N., Peters, B., (2002), "Innovation and Innovation Success in the German Manufacturing Sector, Econometric Evidence at Firm Level". Centre for European Economic Research (ZEW)

[20] Jaumandreu, J., Martín-Marcos, A., (2003), "Entry exit and productivity growth", UNED y Universidad Carlos III de Madrid.

[21] Jaumandreu, J., (2003), "Does innovation spur employment. A firm-level analysis using Spanish CIS data", Universidad Carlos III de Madrid.

[22] Kremp, E., Mairesse, J., (2003) "Knowledge management, innovation and productivity A firm level exploration based on the French CIS3 data". SESSI, CREST-INSEE.

[23] Mairesse, J., Mohnen, P., (2001), "To Be or Not To Be Innovative, An Exercise in Measurement", OECD.

[24] Mairesse, J., Mohnen, P., (2003), R\&D and productivity, A re-examination in light of the innovation surveys". ZEW Workshop: Empirical Economics of Innovation and Patenting. Mannheim, March 14 and 15, 2003.

[25] Mairesse, J., Mohnen, P., . ${ }^{A}$ ccounting for Innovation and Measuring Innovativeness, An Illustrative Framework and an Application". 
[26] Peters, B., (2004), "Employment Effects of Different Innovation Activities", Centre for European Economic Research (ZEW)

[27] Pilat, Dirk (2004) "The ICT Productivity Paradox", OECD.

[28] Piva, M., Vivareli, M., (2003), "Innovation and employment, evidence from Italian Microdata", IZA Discussion Paper No. 730

[29] Rodríguez, Alfredo (2001), "La innovacion como forma de participacion social", Para el libro de Participación Social, Octubre 2001.

[30] Syrneonidis, G., (1996), "Innovation, Firm Size and Market Structure", OECD.

[31] Zwick, T., (1999), "Innovations Induce Asymmetric Employment Movements", Zentrum fur Europaische Wirtschaftsforschung, Mannheim. 
Cuadro 1: Process and product innovation, employment and sales 1998-2001

\begin{tabular}{|l|c|}
\hline Nž of firms & 558 \\
Non-innovators (\%) & 17.74 \\
Process only (\%) & 4.84 \\
Product innovators* (\%) & 77.42 \\
\hline & \\
\hline Employment growth (\%) & \\
All firms & 5.6 \\
Non-innovators & -3.3 \\
Process only & 25.4 \\
Product innovators* & 6.3 \\
\hline & \\
\hline Old product sales growth (\%) & \\
All firms & 6.3 \\
Non-innovators & 5.7 \\
Process only & 16.2 \\
Product innovators* & 5.8 \\
\hline & \\
\hline New product sales growth (\%) & \\
All firms & 23.6 \\
Non-innovators & 3.8 \\
Process only & 12.7 \\
Product innovators* & 28.6 \\
\hline & \\
\hline Productivity growth (\%) & 5.8 \\
All firms & 2.6 \\
Non-innovators & 13.2 \\
Process only & 7.7 \\
\hline Product innovators* & \\
\hline & 16.4 \\
\hline Prices growth (\%) & \\
Non-innovators & \\
Process only & \\
Product innovators* & \\
\hline
\end{tabular}

* Includes only products innovators and both product and process innovators. 
Cuadro 2: Preliminary OLS regression

Dependant Variable: $\ell$

\begin{tabular}{|l|c|c|c|}
\hline Variable & Coef. & Robust Std. Err. & $\mathrm{P}>|\mathrm{t}|$ \\
\hline Sales Growth $(g-\pi *)$ & .2008148 & .0538789 & 0.000 \\
\hline Only process Inn. & .2401199 & .1989656 & 0.228 \\
\hline Product Inn & .0552962 & .054405 & 0.310 \\
\hline Constant & .3207913 & .340821 & 0.347 \\
\hline
\end{tabular}

Cuadro 3: Innovation effects on employment

Dependant Variable: $\ell-\left(g_{1}-\pi_{1} *\right)$

Panel A: OLS Regression

\begin{tabular}{|l|c|c|c|}
\hline Variable & Coef. & Robust Std. Err. & $\mathrm{P}>|\mathrm{t}|$ \\
\hline New Product Sales Growth & .3334921 & .0888194 & 0.000 \\
\hline Constant & -.8008641 & .4199799 & 0.057 \\
\hline
\end{tabular}

Panel B: IV Regression

Instrument used: novel inputs utilization as an origin of the innovation idea.

\begin{tabular}{|l|c|c|c|}
\hline Variable & Coef. & Robust Std. Err. & $\mathrm{P}>|\mathrm{t}|$ \\
\hline New Product Sales Growth & .5271609 & .1999712 & 0.009 \\
\hline Constant & -.7817513 & .4184707 & 0.062 \\
\hline
\end{tabular}

Panel C: IV Regression

Instrument used: increased range, clients as source of information, permanent $\mathrm{R} \& \mathrm{D}$ engagement.

\begin{tabular}{|l|c|c|c|}
\hline Variable & Coef. & Robust Std. Err. & $\mathrm{P}>|\mathrm{t}|$ \\
\hline New Product Sales Growth & .5250649 & .2018703 & 0.010 \\
\hline Constant & -.7819582 & .4181616 & 0.062 \\
\hline
\end{tabular}


Cuadro 4: The effects of process innovation on employment

Dependant Variable: $\ell-\left(g_{1}-\pi_{1} *\right)$

Panel A: OLS Regression

\begin{tabular}{|l|c|c|c|}
\hline Variable & Coef. & Robust Std. Err. & $\mathrm{P}>|\mathrm{t}|$ \\
\hline New Product Sales Growth & .3345315 & .088587 & 0.000 \\
\hline Only Process Innovation & .0847377 & .2326491 & 0.716 \\
\hline Constant & -.8103339 & .4119856 & 0.050 \\
\hline
\end{tabular}

Panel B: IV Regression

Instrument used: novel inputs utilization as an origin of the innovation idea.

\begin{tabular}{|l|c|c|c|}
\hline Variable & Coef. & Robust Std. Err. & $\mathrm{P}>|\mathrm{t}|$ \\
\hline New Product Sales Growth & .5451896 & .191504 & 0.005 \\
\hline Only Process Innovation & .0956653 & .2310632 & 0.679 \\
\hline Constant & -.7907789 & .4114864 & 0.055 \\
\hline
\end{tabular}

Panel C: IV Regression

Instrument used: novel inputs utilization as an origin of the innovation idea and increased range.

\begin{tabular}{|l|c|c|c|}
\hline Variable & Coef. & Robust Std. Err. & $\mathrm{P}>|\mathrm{t}|$ \\
\hline New Product Sales Growth & .5457267 & .190111 & 0.004 \\
\hline Only Process Innovation & .0956932 & .2308574 & 0.679 \\
\hline Constant & -.7907291 & .4114105 & 0.055 \\
\hline
\end{tabular}

All regressions have been controlled by investment and economic sector. 